\title{
RANCANG BANGUN SALES FORCE AUTOMATION BERBASIS ANDROID DI PT. $X$
}

\author{
Glenda Sogo Fanrensen ${ }^{1}$, Yulia ${ }^{2}$, Adi Wibowo ${ }^{3}$ \\ Program Studi Teknik Informatika Fakultas Teknologi Industri Universitas Kristen Petra \\ Jl. Siwalankerto 121-131 Surabaya 60236 \\ Telp. (031) 2983455, Fax. (031) 8417658 \\ Email: m26410072@john.petra.ac.id ${ }^{1}$, yulia@petra.ac.id ${ }^{2}$, adiw@ petra.ac.id ${ }^{3}$
}

\begin{abstract}
Abstrak: Dalam menjalankan proses penjualan, PT. X melakukan proses pemasukan data secara manual. Saat di lapangan, Sales Force harus mencatat pesanan dari para customer secara manual, dan nantinya memasukkan ulang dalam bentuk data di kantor pusat. Proses penyalinan data yang berulang menyebabkan data rentan terhadap kesalahan ketik dan tidak up-to-date karena menunggu kepulangan Sales Force yang berminggu-minggu. Permasalahan lain yaitu banyaknya kertas yang terbuang dalam proses penjualan, seperti Sales Order (SO) dan Invoice. Di samping itu, PT. X juga membutuhkan dukungan dokumen yang lengkap yang dapat digunakan oleh tenaga penjualan untuk memenuhi kebutuhan informasi customer. Dalam penelitian ini dipilihlah software Sales Force Automation (SFA) yang bekerja secara online sebagai solusi yang dapat membantu mengotomasi data penjualan. Untuk penyediaan dokumen, dikarenakan ada banyak dokumen yang harus disediakan, maka dibuatlah taksonomi bisnis untuk dokumen-dokumen tersebut. Dikarenakan software menuntut untuk dapat diakses di mana pun dan kapan pun, dipilihlah Android sebagai hardware $\neg$ nya. Hasil yang diperoleh antara lain program bisa menampilkan, membuat, mengubah, dan menghapus data yang dibutuhkan dalam sistem penjualan serta knowledge base pada PT. X. Program admin mendukung pembuatan penilaian kerja untuk Sales Force, notifikasi, pengkalkulasian perbandingan omzet dan target serta komisi Sales Force, dan lain-lain. Program SFA memungkinkan Sales Force membuat SO yang melalui verifikasi pada customer via SMS Gateway sebelum masuk ke database perusahaan, membuat penjadwalan, dan lain-lain.
\end{abstract}

Kata kunci: Pengotomasian Tenaga Penjualan, Basis Pengetahuan, Taksonomi Bisnis, Android, SMS Gateway.

\begin{abstract}
The existing system of PT. X used to insert sales data manually. While in field, Sales Force noted of the order from dealer/customer manually, then later insert it into company's database. The repetitive data copying causes bigger risk of mistyping and unreliability, because Sales Force travels for weeks. Other problem is that too many paper wasted on Sales Order and Invoice. Furthermore, PT. X needs comprehensive document support for Sales Force to fulfill customer's need of information. In this research, Sales Force Automation (SFA) software that works online is chosen to meet the expectations. For document supply, due to the amount of documents needed, business taxonomy is made. Because the software is demanded to be easily accessed from wherever and whenever, Android is chosen as the hardware. The results obtained are various features for sales data management, such as view, add, edit, delete, and verification. The admin program supports the Sales Force work appraisal, notification, calculating Sales Force's earnings per target ratio, Sales Force's commission, et cetera. The SFA program supports the making of Sales Order, which is to be verified through SMS Gateway before inserted into company's database, scheduling, et cetera.
\end{abstract}

Keywords: Sales Force Automation, Knowledge Base, Business Taxonomy, Android, SMS Gateway

\section{PENDAHULUAN}

PT. X adalah perusahaan yang bergerak di bidang industri mesin pertanian, perikanan, dan pengolahan bahan makanan. PT. X berdiri sejak tahun 1942 serta memiliki 7 kantor cabang yang mempunyai jaringan di seluruh Indonesia. PT. X memiliki visi yaitu menjadi perusahaan penyedia peralatan pertanian terbesar di Asia Tenggara. Berdasarkan visi tersebut PT. X berusaha mewujudkannya dengan misi memasarkan peralatan pertanian dengan harga yang sewajarnya dan untuk membantu Pemerintah menciptakan pertumbuhan ekonomi yang stabil. Dalam rangka memperoleh kesuksesan di dalam usaha tersebut, PT. X secara terus menerus mengembangkan teknologi tepatguna, manajemen profesional dan memberikan layanan yang terbaik kepada pelanggan.

Dalam menjalankan proses penjualan, PT. X melakukan proses pemasukan data secara manual. Saat di lapangan, tenaga penjualan harus mencatat 
pesanan dari para dealer secara manual, dan nantinya harus memasukkan ulang dalam bentuk data di kantor pusat. Proses penyalinan data yang berulang ini menyebabkan data menjadi rentan terhadap kesalahan ketik. Selain itu data di kantor pusat menjadi tidak upto-date karena menunggu kepulangan tenaga penjualan yang bisa sampai berminggu-minggu, oleh sebab itu menyebabkan data Sales Order (SO) menjadi kurang reliable. Permasalahan lain yang timbul adalah banyaknya kertas yang terbuang dalam proses penjualan PT. X, seperti SO dan Invoice.

Dalam penelitian ini dipilihlah software Sales Force Automation (SFA) yang bekerja secara online sebagai solusi yang dapat membantu mengotomasi data penjualan, karena dengan pengotomasian tersebut diharapkan dapat meminimalkan kesalahan dalam pemasukan data, mengurangi penggunaan kertas yang tidak perlu, dan meningkatkan reliabilitas data. Selain itu, karena software ini menuntut untuk dapat diakses di mana pun dan kapan pun dalam pengoperasiannya, dipilihlah Android sebagai pirantinya.

Selain permasalahan di atas, PT. X juga membutuhkan dukungan dokumen yang lengkap yang dapat digunakan oleh Sales Force untuk memenuhi kebutuhan informasi dealer/customer, misalnya kelebihan dan kekurangan produk, harga produk, spesifikasi produk, studi kelayakan produk, dll. Karena ada banyak dokumen yang harus disediakan oleh PT. X, maka diperlukan adanya pembuatan taksonomi bisnis untuk dokumen-dokumen tersebut.

\section{SALES FORCE AUTOMATION (SFA)}

\section{Pengertian SFA}

SFA adalah aplikasi berbasis teknologi informasi yang mendukung fungsi kerja penjualan[1]. Teknologi informasi yang dimaksud terdiri dari hardware dan software. Software merupakan pengaplikasian SFA itu sendiri, sementara hardware tidak terbatas kepada desktop atau laptop saja namun juga berbagai device yang dibutuhkan.

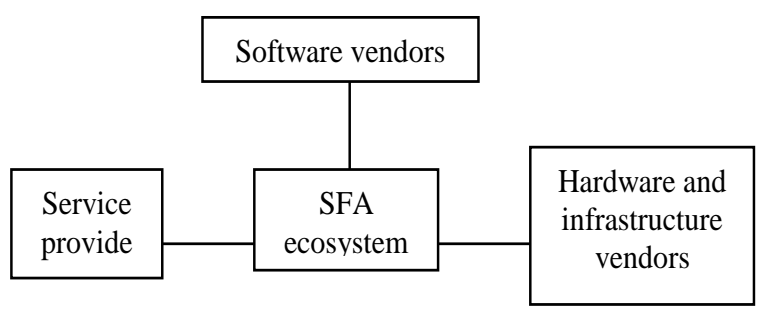

Gambar 1. Diagram Ekosistem SFA

SFA tidak mampu berdiri sendiri. Ada banyak aspek yang mendukung jalannya SFA. Dari diagram pada Gambar 1 dapat diketahui bahwa SFA tidak bisa berjalan hanya dengan vendor software namun SFA juga membutuhkan hardware sebagai wadah untuk menjalankan software tersebut seperti Android. Selain itu, proyek SFA yang sudah kompleks kerap membutuhkan koneksi internet.

SFA didesain untuk membantu Sales Force dalam mendapatkan dan mempertahankan customer, mengurangi waktu administrasi, dan menyediakan pengaturan akun yang kuat[2]. SFA adalah sistem berbasis teknologi yang secara otomatis menyimpan tahap-tahap dalam proses penjualan. SFA dengan cepat menjadi standar bagi perusahaan manapun yang memiliki Sales Force.

Sementara itu, hasil penelitian mengenai faktor yang mendorong perusahaan dalam mengimplementasikan SFA dapat dilihat di Tabel 1.

Tabel 1. Motivasi perusahaan dalam mengimplementasikan SFA

\begin{tabular}{lc}
\hline \multicolumn{1}{c}{ Motivation } & \% of sample reporting \\
\hline Improve efficiencies & 72 \\
Improve customer contact & 44 \\
Increase sales & 33 \\
Reduce costs & 26 \\
Improve accuracy & 21 \\
\hline
\end{tabular}

Sumber: Erffmeyer dan Johnson (2001)[3].

\section{METODE SFA}

\section{Metode Taksonomi Bisnis}

Konsep dari taksonomi didasarkan pada pengelompokan (categorizing) komponen-komponen konsep ke dalam struktur yang logis[4]. Taksonomi tradisional biasanya menggunakan aturan-aturan pengelompokan yang detail, tidak boleh berulang dalam klasifikasinya, dan ketelitian (granularity) yang sangat tinggi. Tetapi karena perkembangan teknologi saat ini yang membuat knowledge base digunakan oleh jenis pengguna yang lebih luas, maka konsep taksonomi tradisional lebih sering gagal. Sebagai contoh staf umum dalam sebuah perusahaan cenderung tidak menemukan keuntungan penggunaan taksonomi. Taksonomi bisnis didesain lebih utamanya untuk klasifikasi, dan untuk usability. Taksonomi bisnis sering digunakan untuk klasifikasi metadata dari knowledge, navigasi bagi user interface, atau keduanya. Taksonomi bisnis yang baik harus didesain agar intuitif bagi seluruh jenis pengguna.

Aturan-aturan dalam taksonomi bisnis adalah:

1. Taksonomi menggunakan istilah-istilah yang sederhana. Hindari penggunaan jargon-jargon, atau istilah teknis yang kompleks. Desainer taksonomi 
harus menggunakan prinsip 'lowest common denominator', yaitu bahwa setiap istilah harus dipahami oleh sebanyak mungkin pengguna yang paling umum. Ketika pengguna melihat level paling tinggi dari sebuah taksonomi pengguna harus langsung dapat memahami apa yang sedang mereka lihat, dan dapat melanjutkan pencarian menuju konsep yang dicari.

2. Taksonomi tradisional menggunakan hirarki konsep yang sangat panjang. Seringkali terdapat 100 node pada level tertinggi, dan setiap node dapat memiliki sekitar 12 level hirarki. Taksonomi bisnis sebaiknya memiliki rata-rata 8 node pada level tertinggi, dan 3 level hirarki. Penggunaan tree yang lebih kecil dapat memastikan pengguna memahami keseluruhan konsep dan klasifikasi konsep dalam taksonomi tersebut.

3. Karakteristik lain adalah fleksibilitas. Karena kebutuhan sebuah bisnis selalu berubah, maka klasifikasi konsep harus mendukung evolusi taksonomi dalam jangka panjang sesuai umpan balik dari pengguna. Untuk mencapai hal ini diperlukan metode pengembangan taksonomi yang iteratif, yaitu evaluasi terus menerus dari taksonomi yang telah dibuat.

Langkah-langkah dalam pembuatan taksonomi:

1. Pengumpulan data

Mengumpulkan data yang akan dikategorikan dengan cara melakukan wawancara untuk sedikit sampel atau mengumpulkan dokumendokumen yang diperlukan,

2. Pengkategorian

Dari data yang sudah didapat dan dipelajari secara mendalam satu-persatu, langkah selanjutnya adalah membuat pengkategorian. Proses ini dilakukan dengan cara mencari kata-kata kunci yang sering muncul dari dokumen-dokumen tersebut, mengumpulkan, dan menyusunnya menjadi suatu hierarki tree.

3. Berkonsultasi pada ahli

Mengkonsultasikan pengkategorian yang sudah dibuat di langkah sebelumnya pada orang yang menguasai data dan merevisinya jika ada koreksi dari sang ahli.

4. Melakukan survei

Survei dilakukan terhadap end-user dari taksonomi. Survei penting untuk dilakukan untuk menguji apakah taksonomi telah menjawab kebutuhan. Contoh survei yaitu dengan cara melakukan wawancara pada end-user.

5. Merevisi pengkategorian

Dari hasil kuisioner, dilakukan beberapa penyesuaian dan perubahan pada pengkategorian.
6. Membuat pengkategorian final

Setelah mendapat beberapa masukan dari berbagai pihak, didapatkan model taksonomi final.

\section{ANALISIS SISTEM}

\section{Analisis Proses Penjualan}

Sistem penjualan PT. X ada dua macam, yaitu direct sales dan door-to-door campaign. Direct sales yaitu dealer/customer datang ke kantor cabang untuk membeli barang. Sementara door-to-door campaign adalah tenaga penjualan mendatangi dealer/customer untuk menawarkan barang dan melakukan transaksi penjualan. Keduanya memiliki alur yang sama, hanya pelakunya saja yang berbeda. Pada direct sales, yang berhubungan langsung dengan dealer/customer adalah admin dari kantor cabang, sementara pada doorto-door campaign, yang berhubungan langsung dengan dealer/customer adalah tenaga penjualan.

Pertama-tama adalah dilakukan pembuatan SO. Tenaga penjualan yang mendatangi dealer/customer atau admin kantor cabang akan membuat SO rangkap tiga. Setelah ditandatangani oleh dealer/customer, rangkap pertama dari SO akan dijadikan arsip kantor, rangkap kedua untuk arsip divisi, sementara rangkap terakhir untuk arsip administrasi. Setelah SO diterima oleh divisi produk, staf divisi akan mengecek stok dari barang tersebut. Setelah barang dipastikan ada, barulah Surat Jalan (SJ) dibuat oleh sekertaris divisi. SJ dibuat dua rangkap lalu diberikan kepada staf logistik/ekspedisi beserta barang pesanan. Selanjutnya, staf logistik/ekspedisi mengirim barang beserta kedua SJ untuk ditandatangani. SJ yang asli dibawa oleh dealer/customer sementara kopiannya dibawa kembali ke PT. X. Setelah SJ kembali barulah Invoice dibuat sebanyak dua rangkap. Invoice kembali diberikan kepada dealer/customer untuk ditandatangani, dan bukti pembayaran beserta kopian Invoice yang telah ditandatangani akan dibawa kantor cabang untuk disimpan sebagai arsip administrasi.

Untuk dealer/customer baru, ada sedikit pengecualian yaitu Invoice diberikan kepada dealer/ customer bersamaan dengan SJ dan barang yang dipesan.

\section{Analisis Kebutuhan}

Dari latar belakang masalah bisa disimpulkan bahwa kebutuhan perusahaan meliputi:

- Software SFA berbasis Android yang berhubungan langsung dengan database pusat untuk diaplikasikan pada Android milik Sales Force.

- Software bersifat online, artinya kantor bisa memantau kinerja Sales Force dan melihat 
perubahan yang dibuat segera setelah perubahan dilakukan.

- Pembuatan laporan-laporan berupa SO dan Invoice dalam bentuk data di Android (tanpa dicetak).

- Pembuatan knowledge base berbentuk Taxonomy, untuk mempermudah mengkategorikan banyaknya dokumen.

- Taxonomy dilengkapi dengan fitur search yang didukung oleh SOLR untuk mengoptimalkan pencarian.

\section{DESAIN SISTEM}

\section{Taksonomi Bisnis}

Konsep dari taksonomi didasarkan pada pengelompokan (categorizing) komponen-komponen konsep ke dalam struktur yang logis[4]. Hasil akhir desain taksonomi untuk Sales Force PT. X dapat dilihat pada Gambar 2.

\section{Data Flow Diagram (DFD)}

DFD akan menjelaskan aliran proses keluar masuk pada PT. X. Pembuatan DFD dimulai dengan pembuatan context diagram, di mana merupakan gambaran sistem secara keseluruhan. Setelah pembuatan context diagram, dapat dibuat level 0,1 , dan selanjutnya jika diperlukan untuk menggambarkan proses aliran yang jelas[5].

Dapat dilihat di Gambar 3 ada 4 proses utama dalam DFD sistem penjualan PT. $X$ yaitu Maintain Data Master, Transaksi, Laporan, dan Penilaian Kerja. Entitas-entitas yang terlibat adalah Customer, Admin Kantor Pusat, Marketing, Sales Force, Logistik.

\section{Entity Relationship Diagram (ERD)}

ERD adalah diagram yang dipakai untuk mendokumentasikan skema database dan disebut juga sebagai entity relationship karena menggambarkan entitas dan hubungannya[5]. Dalam pembuatan ERD terdapat 2 bagian, yaitu conceptual data model dan physical data model.

ERD dalam bentuk conceptual data model dapat dilihat pada Gambar 4. Tabel-tabel yang digunakan pada sistem penjualan PT. X meliputi 25 tabel yaitu Article, Notification, Category, Employee, Tag, Position, Department, CustomerTemp, LPK, Notif, Salesman, Komisi, TargetSales, SOTemp, DetailSOTemp, SO, DetailSO, Customer, Schedule, rpiut2, THInvo, TInvo, StockG, Complaint, dan ComplaintCategory.

\begin{tabular}{|c|c|c|c|}
\hline 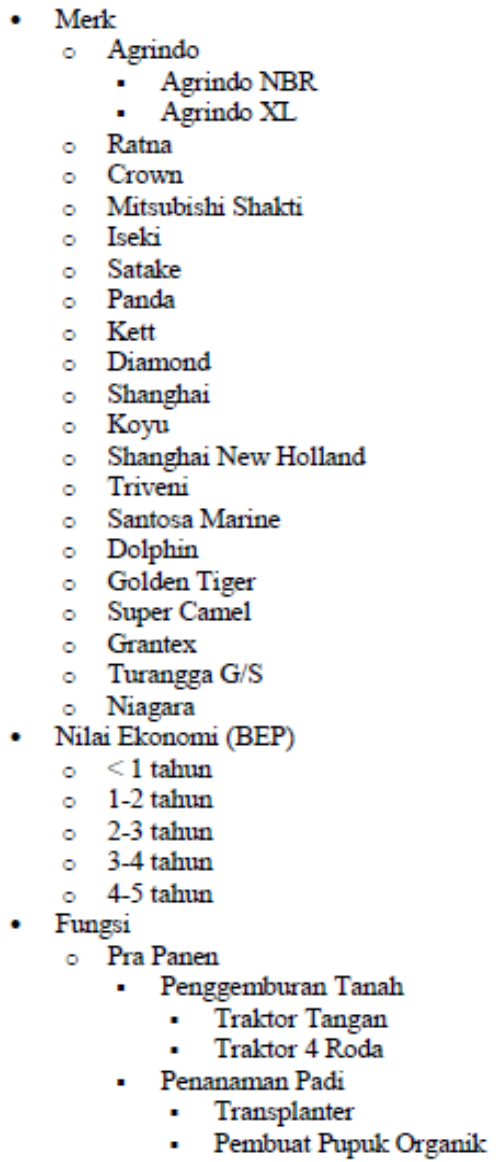 & 0 & 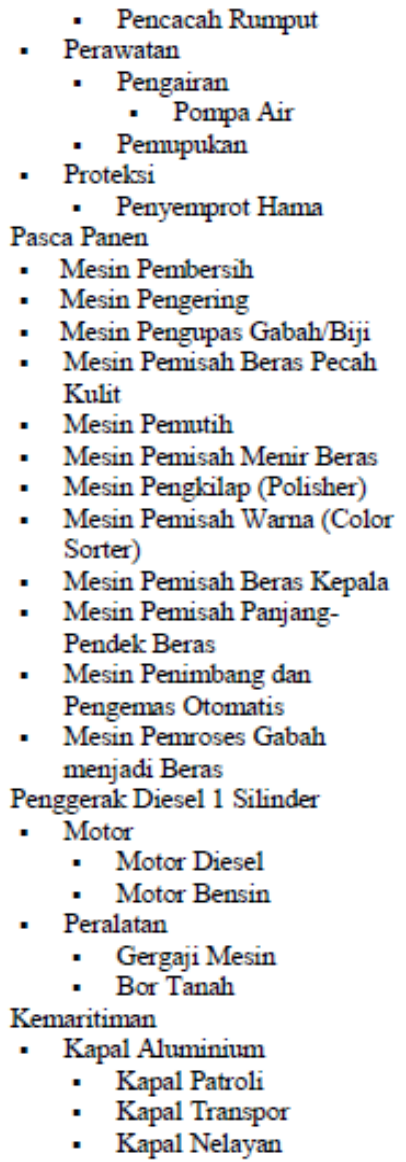 & 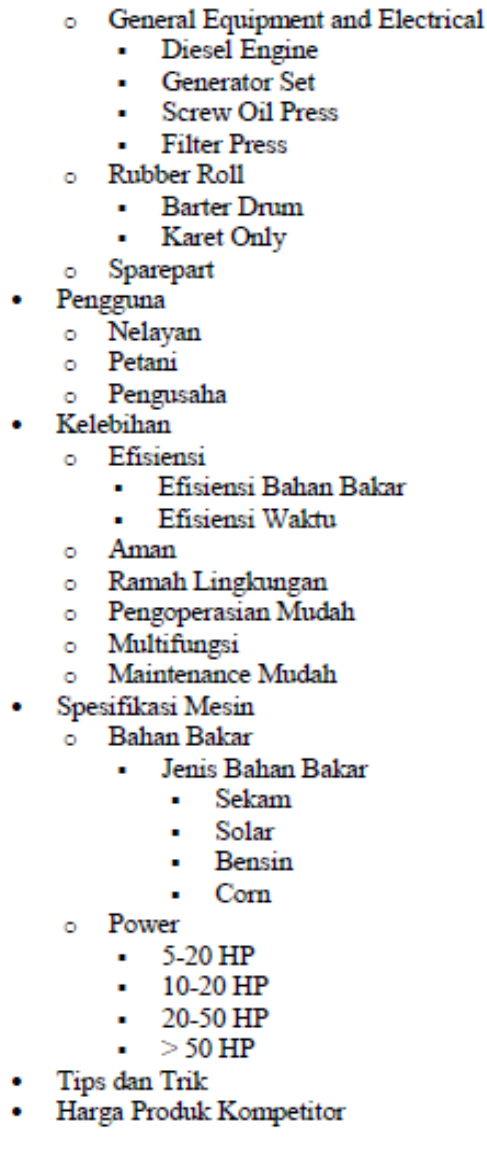 \\
\hline
\end{tabular}

Gambar 2. Desain Taksonomi Bisnis PT. X 


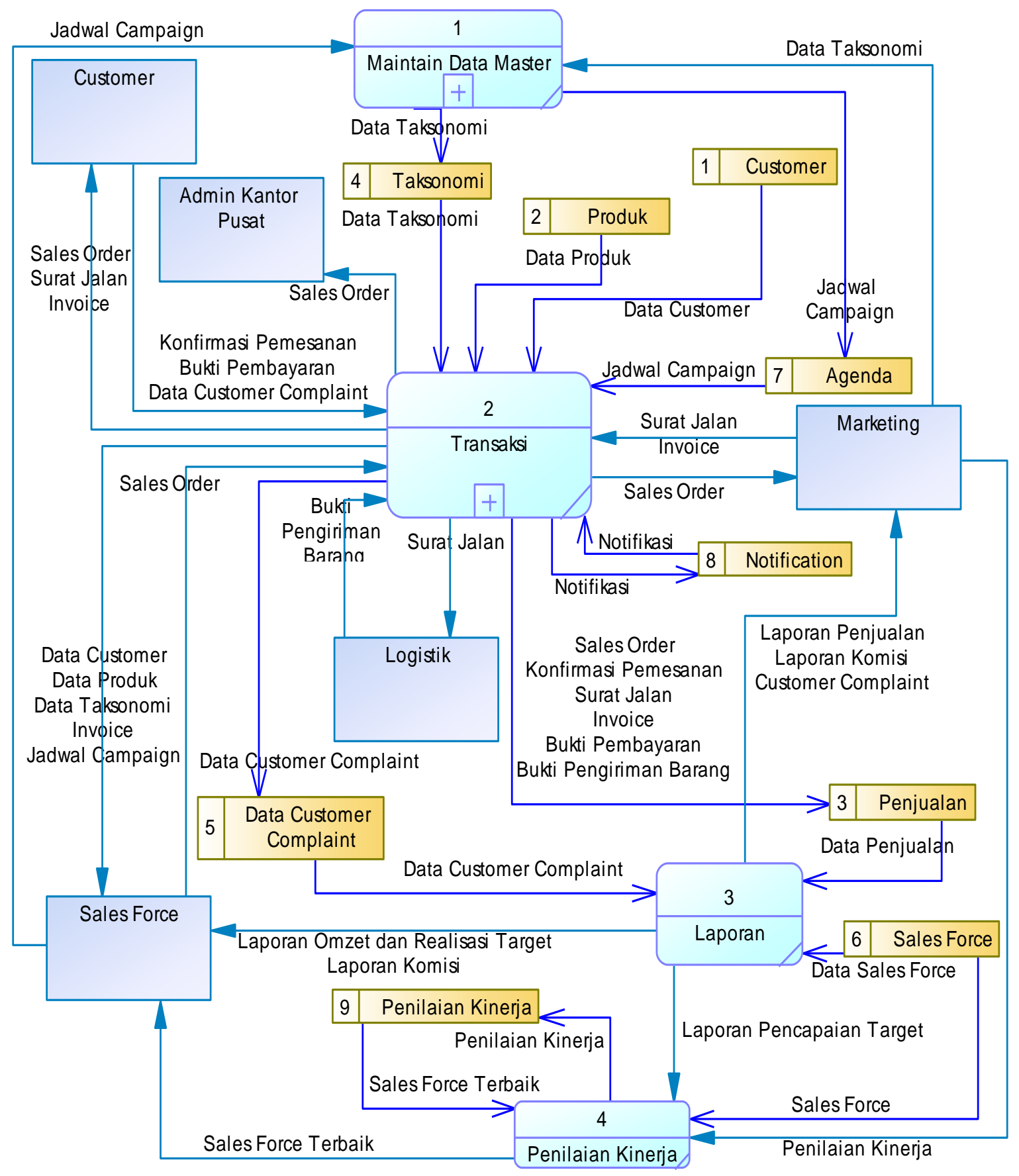

Gambar 3. DFD level 0 


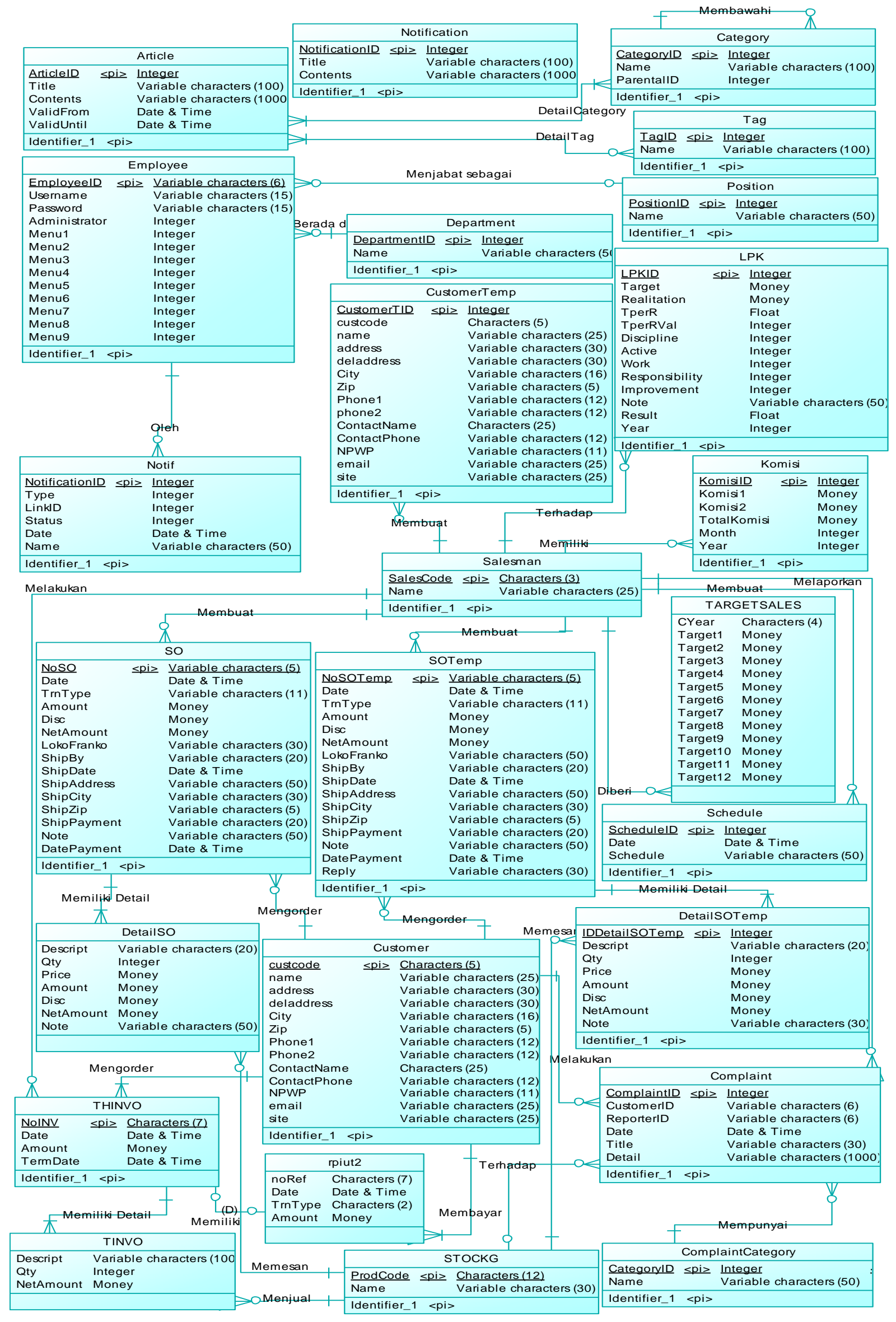

Gambar 4. ERD Conceptual Model 


\section{IMPLEMENTASI SISTEM}

\section{Taksonomi}

Taksonomi Bisnis terdiri dari artikel-artikel, yang pertama harus dibuat terlebih dahulu, seperti pada Gambar 5. Contoh data yang dimasukkan adalah artikel berjudul "Tips dan Trik dalam Memprospek" dengan tanggal validasi "24 November 2013" hingga "24 November 2014". Selain itu ditambahkan kategorinya yaitu "Tips dan Trik".

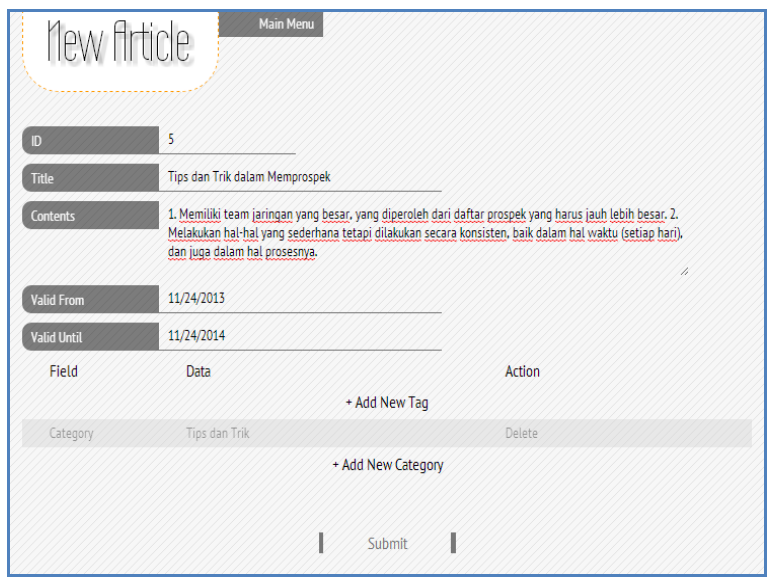

Gambar 5. Halaman Add Article

\section{Transaksi}

$\underline{\text { Pembuatan SO }}$

Mula-mula, SO dibuat oleh Sales Force. Sebagai contoh pada Gambar 6, data SO dengan dealer/ customer bernama " 1060 ", pada tanggal " $11 / 25 / 2013$ ", produk "NI GTR-4"" dengan harga "3.200.000" sebanyak "2". Barang akan dibayar dan dikirim tanggal "11/30/2013" dengan ekspedisi "PT. X", ke alamat "Siwalankerto 121", kota "Surabaya".

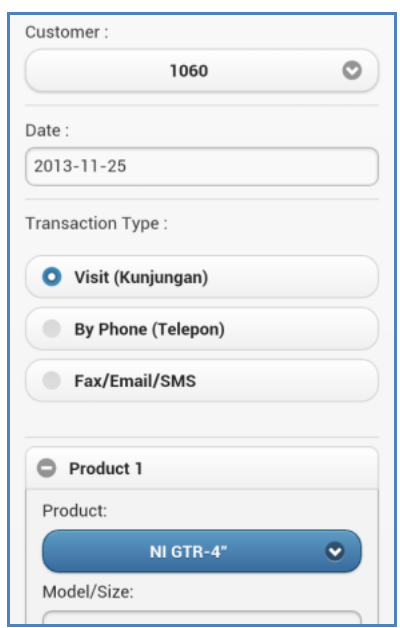

Gambar 6. Pembuatan SO

\section{$\underline{\text { Verifikasi SO }}$}

Sebelum SO masuk ke database perusahaan, terlebih dahulu akan diverifikasi. Verifikasi SO dilakukan dengan bantuan konfirmasi dari dealer/ customer yang bersangkutan dengan melakukan komunikasi via SMS Gateway. Format SMS untuk dealer/customer dapat dilihat pada Gambar 7.

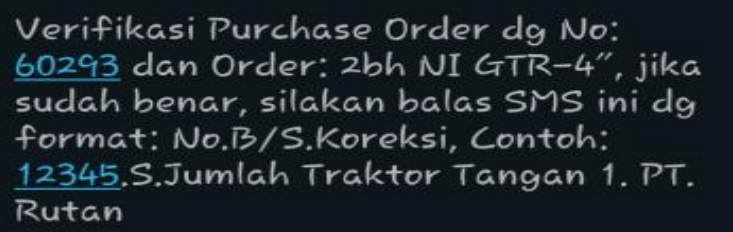

Gambar 7. Format SMS

\section{$\underline{\text { Scheduling }}$}

Sales Force dapat membuat dan mengatur penjadwalan bagi dirinya sendiri. Hal ini dimaksudkan agar kinerjanya semakin efektif dan tertata. Tampilan master bisa terlihat pada Gambar 8.

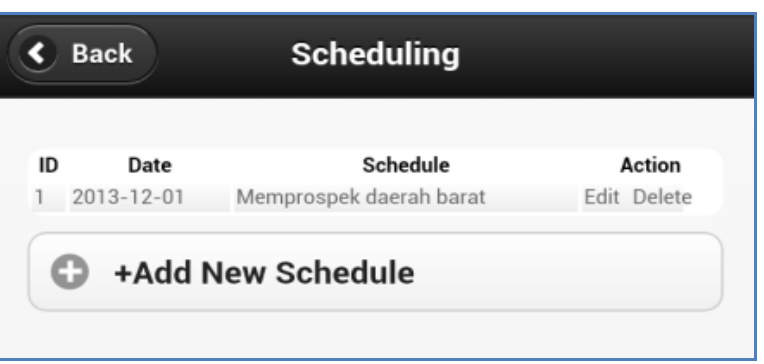

\section{Gambar 8. Scheduling}

\section{Penilaian Kinerja}

Selain difasilitasi, Sales Force juga diberi penghargaan akan semakin terpacu dalam menghasilkan lebih. Penghitungan penilaian kinerja Sales Force di PT. X yaitu $50 \%$ dari perbandingan omzet dan target Sales Force, dan 50\% lagi dari penilaian kualitatif. Penilaian kualitatif sendiri meliputi disiplin kerja, keaktifan kerja, hasil kerja, tanggung jawab, dan peningkatan yang masing-masing bobotnya adalah 20\%. Pada Gambar 9 berikut terdapat tampilan penilaian kinerja.

\section{Notification}

Untuk menjaga agar komunikasi Sales Force dengan kantor pusat tidak terputus sepenuhnya begitu Sales Force melakukan sales campaign, terdapat fitur yang memungkinkan kantor pusat memberikan notifikasi jika ada hal-hal penting yang harus segera diketahui Sales Force. Gambar 10 menunjukkan tampilan notifikasi pada program SFA. 


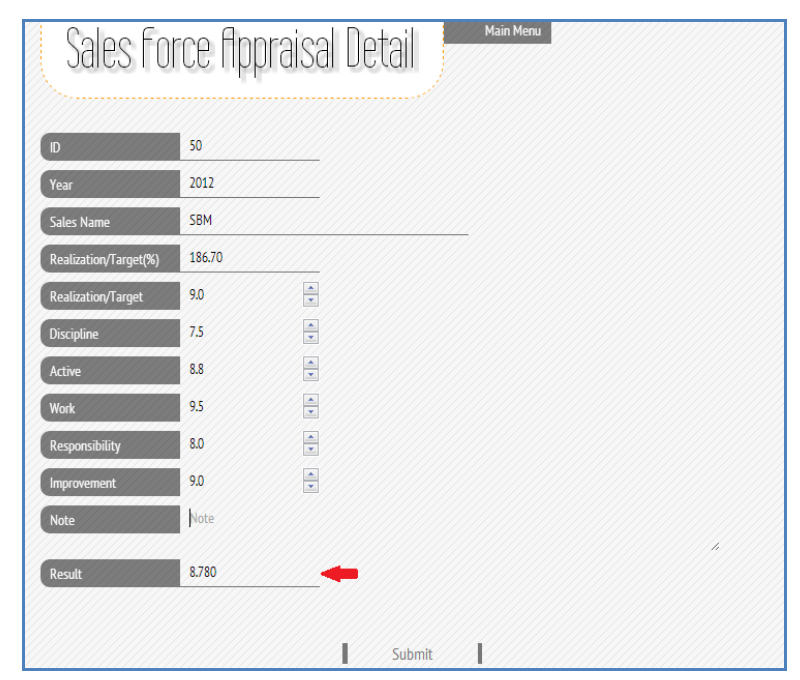

Gambar 9. Penilaian Kinerja Sales Force

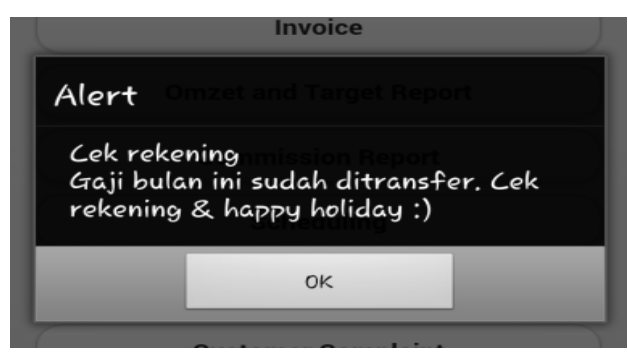

Gambar 10. Notifikasi

\section{Customer Complaint}

Program juga menyediakan fitur untuk menampung keluhan dari customer. Dengan disimpannya keluhan-keluhan, maka divisi Marketing di PT. X bisa menentukan penyelesaian dari masalah/keluhan tersebut. Tampilan penyimpanan customer complaint dapat dilihat di Gambar 11.

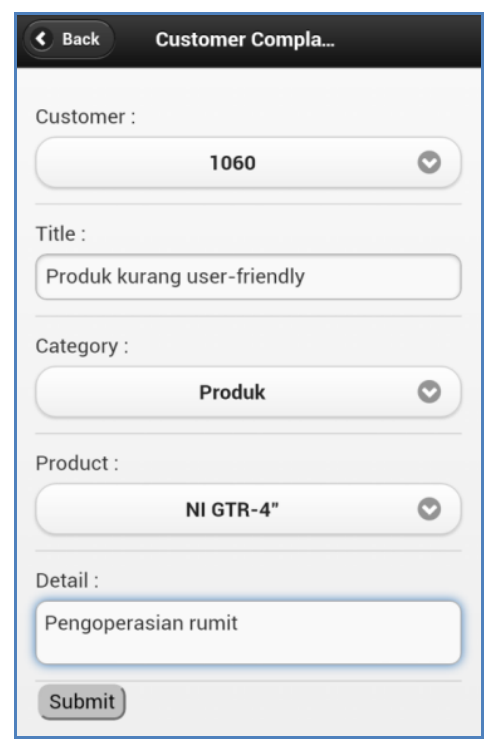

Gambar 11. Customer Complaint

\section{Laporan}

Jenis-jenis laporan yang ada yaitu laporan penjualan, komisi, serta pencapaian target. Laporan penjualan dapat dilihat berdasarkan waktu, Sales Force, maupun dealer/customer. Laporan komisi menunjukkan besarnya komisi masing-masing Sales Force dalam periode bulan. Laporan pencapaian target dihasilkan dari omzet dan target lalu dibandingkan antara keduanya. Masing-masing laporan bisa dilihat dalam bentuk tabel, grafik, serta siap cetak dalam bentuk dokumen Word. Contoh format laporan bisa dilihat di Gambar 12.

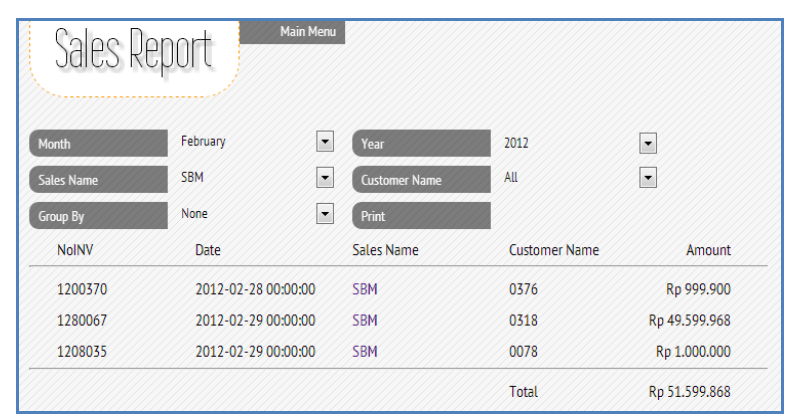

Gambar 12. Laporan Penjualan oleh Sales Force SBM

\section{KESIMPULAN \& SARAN}

Dari hasil perancangan dan pembuatan perangkat lunak SFA di PT. X, dapat diambil beberapa kesimpulan antara lain:

- Sistem dapat melakukan komunikasi data dengan program SFA secara online melalui sinkronisasi data sehingga data menjadi lebih up-to-date.

- Sistem dapat mendukung fleksibilitas taksonomi bisnis dengan melakukan pembuatan, penghapusan, pengubahan data.

- Data yang dibuat/diubah oleh Sales Force harus melalui verifikasi terlebih dahulu sebelum masuk ke database perusahaan.

- Sistem dapat menampilkan hasil kerja masingmasing Sales Force, baik dalam omzet, pencapaian target, maupun komisi, serta grafik pergerakannya dalam lingkup tahun. Laporan-laporan tersebut juga dapat dicetak.

- Sistem dapat membuat notifikasi yang diterima program SFA secara online.

- Berdasarkan hasil pengujian, hasil perhitungan Realisasi dibanding Target sama dengan penghitungan manual.

- Berdasarkan hasil pengujian, hasil perhitungan rata-rata hasil penilaian dari segi omzet (per target) dan kualitatif (disiplin kerja, keaktifan kerja, hasil kerja, tanggung jawab, peningkatan) sama dengan penghitungan manual. 
- Program dapat mendukung Sales Force dalam membuat SO secara online sehingga bebas dari penggunaan kertas yang tidak perlu.

- Program dapat mengirim SMS otomatis kepada customer/dealer melalui SMS Gateway sehingga memungkinkan adanya konfirmasi secara langsung dari customer/dealer sebelum SO dimasukkan database.

- Program bisa menampilkan taksonomi bisnis dengan pengkategorian yang terstruktur serta, berdasarkan hasil kuisioner, mudah dimengerti. Artikel-artikel tersebut juga bisa diakses melalui tag-tag pada masing-masing artikel atau dengan melakukan pencarian dengan menuliskan kata kunci yang ingin dicari. Pencarian dilakukan melalui program SOLR sehingga hasil lebih optimal.

- Pencatatan keluhan customer/dealer dapat masuk ke database secara online.

- Dengan adanya program ini, Sales Force bisa melihat, membuat, mengubah, dan menghapus rencana sales campaign untuk dirinya sendiri sehingga jadwalnya lebih tertata.

- Dengan adanya program ini, Sales Force bisa melihat daftar Invoice yang belum lunas untuk membantu dalam menagih customer/dealer. Sales Force juga bisa melihat hasil kerjanya dalam komisi maupun pencapaian target

Saran yang dapat membantu menyempurnakan program:
- Penambahan fitur-fitur berupa rumus penghitungan BEP, tampilan stok barang, dan informasi restock barang pada program SFA.

- Dibutuhkan pengompresan memori dikarenakan data yang terlalu banyak.

\section{DAFTAR PUSTAKA}

1. Buttle, F., Ang, L. \& Iriana, R. (2006). Sales Force Automation: Review, Critique, Research Agenda. International Journal of Management Reviews, 8(4), 213-231.

2. Damjanovic, S. (2010). Sales Force Automation "The Competitive Imperative". Unpublished undergraduate thesis, University of Florida.

3. Erffmeyer, R.C. \& Johnson, D.A. (2001). An Exploratory Study of Sales Force Automation Practices: Expectations and Realities. Journal of Personal Selling \& Sales Management, 21(2), 167-175.

4. Wahl, Z. (2006). Business Taxonomy. Retrieved: October 7, 2013, from http://www.ikmagazine. $\mathrm{com} / \mathrm{xq} / \mathrm{asp} / \mathrm{txtSearch}$.Taxonomies/exactphrase. 1/sid.0E4B1CAB-3D69-4FD5-9585-C61E5A 7A63FE/articleid.CCC7D81E-F161-48F3-AD1B560CA65BB395/qx/display.htm.

5. Romney, Marshall B. (2003). Accounting Information System (9th ed.). New Jersey: PrenticeHall, Inc. 